\title{
EXPLORING HOW EXPERT BEHAVIOURAL DESIGNERS IDEATE IN THE BEHAVIOURAL DESIGN SPACE
}

\author{
C. K. E. B. B. Nielsen ${ }^{凶}$, J. Daalhuizen and P. Cash \\ DTU-Technical University of Denmark, Denmark \\ $\triangle$ ckeni@dtu.dk
}

\begin{abstract}
Behavioural design is a critical means to address challenges surrounding human behaviour. However, practitioners and researcher face difficulties in synthesising relevant perspectives from across fields as behavioural challenges are complex and multi-dimensional. Taking a theory-building approach, this study explore how expert behavioural designers navigate in this complex design space by examining the creative outcome of their current ideation practice. The findings reveal that the designers favour 'holding' out of the four identified ideation patterns: holding, shifting, pairing, and mixing.
\end{abstract}

Keywords: behavioural design, design creativity, design practice, case study

\section{Introduction}

Behavioural design is a multi-theory design approach rooted in both design, e.g. human-product interaction theory (e.g. Akrich, 1992; Latour 1992), as well as social and cognitive psychology (e.g. Bronfenbrenner, 1989; Prochaska, 1979; Kahneman, 2011). It differs from other design approaches by focusing on carefully design of 'user-intervention'-interactions as a mean to replace undesired behaviour with desired behaviour (Cash et al., 2017; Nielsen et al., 2018). In creating successful interventions, designers must be able to consider existing behavioural mechanisms, the context in which the intervention-interaction takes place, and possible behavioural outcomes. Hence, the behavioural design solution space both complex and different compared to other design approaches, and this form a significant challenge for designers in understanding and exploring 'the behavioural design space'. In addition, little is known about how experts currently work with challenging behavioural problems. In order to better understand this critical aspect of behavioural design, this study examines the creative outcome of two real world ideation sessions in an established and successful behavioural design agency.

This research study the agency's current ideation practice in coming up with ideas to solve real world behavioural problems provided by clients, hence, the observed practice was neither instructed or interrupted by the research team. Through open and axial coding, idea elements were identified and grouped into concepts, and examined for fixation and variation of six proposed behavioural parameters: cognition, ability, motivation, timing, social and physical context. As such, we examine the creative outcome of the agency's current ideation practice by identifying how each idea element utilise these parameters. The analysis revealed four distinct ideation patterns across generated concepts: holding, shifting, pairing, and mixing. Thus, this study provides a first insight into 'ideation patterns' expert behavioural designers use in ideating solutions to complex behavioural problems. 


\section{Theoretical background}

Creativity, often referred to as the ability to come up with feasible yet novel solutions (e.g. Mumford et al., 2003), is an important factor in any problem-solving task. Creativity is considered an inherent skill in human cognitive functioning (e.g. Ward et al., 1999), and can be developed over time (e.g. Karbach and Schubert, 2013). Guilford (1956) was one of the first to divide creative problem solving (CPS) into two main processes: divergent thinking, associated with ideation and opening up a solution space, and convergent thinking, associated with judgements and narrowing down the solution space (Jauk et al., 2012). Ideation is by definition employing divergent thinking; however, in practice studies show that fixation often hinders creativity (e.g. Jannson and Smith, 1991; Kohn and Smith, 2011; Crilly and Cardoso, 2017). As such, it is critical to understand how designers work with the various parameters of the solution space to be able to foster creativity. Behavioural design is a relatively young field of practice and research, with a number of researchers addressing slightly different angles, including Kahneman's (2011) Two systems, Cialdini's (2007) Influence, Sunstein and Thanler's (2008) Nudging, Tromp et al.'s (2011) Social design, Fogg's (2009a) Persuasive design and Behaviour design (2019). Even though the field is growing (Niedderer et al., 2017) no existing framework explicitly defines the behavioural design solution space (Nielsen et al., 2018); in addition little is known about how designers work during ideation. Given this context, we first define the main parameters of the behavioural design space, before studying how designers work with them. As behavioural design directly draws on behaviour theory (Cash et al., 2017), a gradual consensus drawn from this common root is starting to emerge in six key parameters. First, understanding people's cognition is important, as people process stimuli in two distinct ways: automatic and reflective cognitive processing. This has been addressed by multiple researchers including Chaiken et al.'s (1999) 'Dual-processing', and Kahneman's (2011) 'two systems'. Overall, they both emphasise that cognitive processing happen in two modes: automatic, fast and implicit (system 1), and reflective, slow and explicit (system 2). Second, people need a specific set of abilities (Fogg, 2009b; Michie et al., 2011; Schell, 2014) to successfully interact with the intervention. Ability is often considered on a continuous scale (Fogg, 2009b; Michie et al., 2011), and overall, abilities can be divided into mental and physical abilities (Schell, 2014). Third, Fogg (2009b) and Michie et al. (2011) consider motivation on a continuous scale, and Ryan and Deci (2000) describe three distinct types of motivation including intrinsic (internal) motivations, extrinsic (external) motivations, and 'amotivations' (complete lack of motivation). In addition, motivation, ability and triggers must co-exist at the right moment in time to achieve a desired behavioural response (Fogg, 2009b). Fourth, elaborating further on timing, Wendel (2013) propose that behaviour should be investigated through steps of actions, in line with Miltenberger's (2011) antecedent, behaviour, consequence (ABC) model. This model forms a fundamental model of behaviour that can be leveraged by designers (Cash et al., 2017), where key aspects are that intervention-interactions can happen before, during or after potential undesired behaviours. Fifth and sixth, interventions will as well as every other products exist, directly or indirectly, in the physical world interacting with people (Latour, 1992). Michie et al. (2011) highlight both the social and environmental opportunities in their behaviour model, where the latter refer to the physical world. In addition, 'user-intervention'-interaction(s) takes place on multiple levels, partly because multiple interventions can co-exist in a given context (Tromp et al., 2011). Interventioninteractions can therefore be considered on multiple levels of the physical context including part, products and systems (Andreasen et al., 2015; Rantanen et al., 2017), as well as of the social context including individual, inter-personal and community level (Bronfenbrenner, 1986). These six behavioural parameters: cognition (system 1 / system 2), ability (mental / physical), motivation (intrinsic / extrinsic), timing (before / during / after), social context (individual / interpersonal / community), and physical context (part / product / system), thus form an initial basis for exploring work within the behavioural design space.

\section{Method}

The goal of this research is to explore how expert behavioural designers work within the behavioural design space in ideating solutions to behavioural problems. In doing so, this research 
adopts a theory building approach (Eisenhardt and Greabner, 2007), where a case-based method is used to deliver in-depth insights (Yin, 2013). We observed and recorded the existing ideation practice in an expert behavioural design agency, having years of experience with consulting diverse companies and organisations on behavioural problems. The agency consists of approximately 15 employees with various educational backgrounds including psychology, engineering design, software development etc., all trained in behavioural design as part of their work in the agency. As such, we consider the case company a successful behavioural design agency consisting of expert behavioural designers.

\subsection{Data collection}

The research team was invited to observe and record two ideation sessions, which was conducted according to the company's existing ideation practices: an introduction of the client problem by 1-2 project leaders followed by free group ideation with present employees. As such, the designers worked using their own work practices, on real cases provided by clients, and was neither interrupted or instructed in any way by the research team. Secondary to the observations, we interviewed four employees and the CEO to establish an understanding of the consultancy, and its behavioural design practices to contextualise the findings.

\subsection{Data preparation, coding and analysis}

First, we went through the video material and identified the generated ideas on the smallest grain possible; in this study referred to as idea elements. The idea elements were transcribed and listed linear in time. For simplicity, Cash and Storga's (2015) 'actionable object-verb associated with a potential solution' was used as a characterisation of a distinct idea element. Then, we identified how each idea element utilised the six behavioural design parameters. If an idea element did not provide enough detail to determine how a parameter was utilised, it was given a " 0 " in that particular behavioural parameter. For example: in session 1, idea no. 15 "This week number plates $\mathrm{xxx} \rightarrow \mathrm{xxx}$ have to park over there" was coded as employing rational information processing, non addressing the ability needed, employing external motivation, active before potential illegal parking, operating on a societal level, and as a system:

\section{Session 1, idea element no. 15 [System 2; 0; Extrinsic; Before; Community; System]}

Having a list of idea elements coded according to the six parameters, we grouped them into concepts, here defined as sets of idea elements dealing with the same theme and closely connected in time. We used linkography to determine relationships between idea elements, by examining each idea element in relation to all proceeding idea elements and asking whether a relation existed (Goldschmidt, 2014). In supporting this approach, we used a list of three relationship criteria:

- Direct relations (a following idea element adds additional details including further explanations and/or sub-components)

- Similar idea elements (participant states an idea element is similar to a previous idea element)

- Alternative idea elements (participant states an idea element is an alternative to a previous idea element)

Idea elements were only linked when they occurred within a relatively short amount of time, as people have a limited working memory and can therefore only be expected to link idea elements that they hold in memory. In this study, we applied 15 seconds as a lower boundary. All following identical ideas were excluded from the analysis. Only 'rich' concepts were taken further for analysis, i.e. concepts that consisted of 4 or more idea elements. After preparing the data, we used open coding to identify initial ideation patterns in the concepts. Lastly, we used axial coding to systematically assess how the behavioural parameters were addressed within and across concepts to identify final ideation patterns applied by the designers. Figure 1 illustrates an overview of the research methods and flow of data analysis applied in this study, and Table 1 provides an overview of studied cases as well as collected and analysed data. 


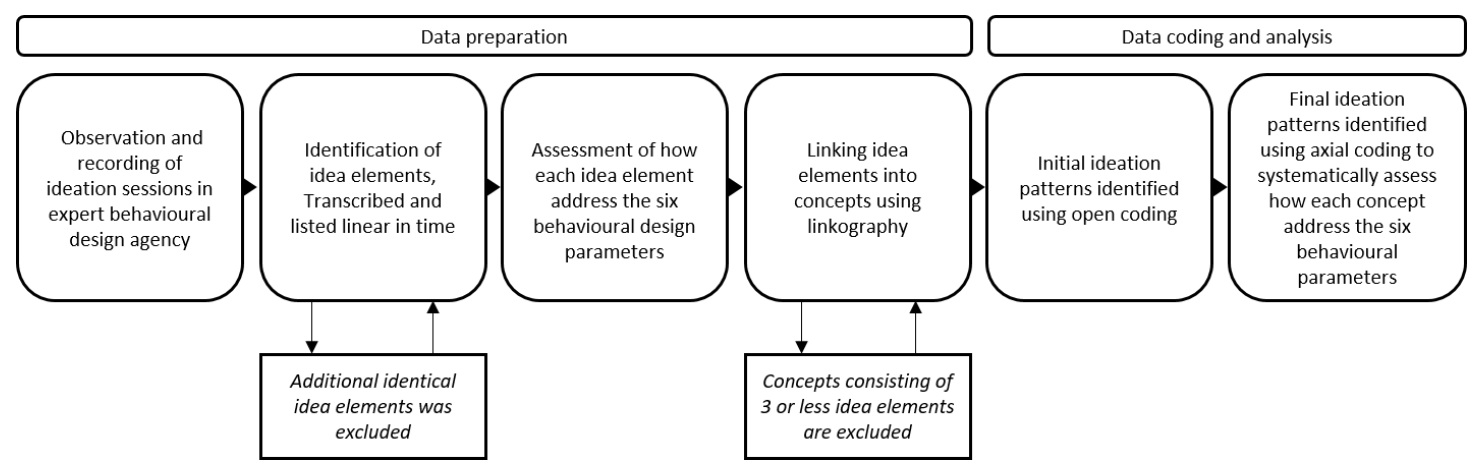

Figure 1. Visualisation of method

Table 1. Overview of case studies and collected data

\begin{tabular}{|l|l|l|}
\hline & S1 & S2 \\
\hline Topic & Preventing illegal parking & $\begin{array}{l}\text { Software support for purchase } \\
\text { and use of [product] }\end{array}$ \\
\hline Video length & $01: 32: 26$ & $00: 58: 20$ \\
\hline $\begin{array}{l}\text { No. of expert behavioural designers } \\
\text { present }\end{array}$ & 4 & 3 \\
\hline Total no. of idea elements identified & 84 & 125 \\
\hline Total no. of concepts identified & 15 & 20 \\
\hline $\begin{array}{l}\text { Total no. of idea elements excluded from } \\
\text { further analysis }\end{array}$ & 30 & 30 \\
\hline
\end{tabular}

\section{Findings}

After analysing the 35 identified concepts, two overall ideation patterns (specific ways in which designers generate ideas and explore the behavioral design solution space) emerged: fixation and variation. Here, fixation refers to when the designers hold the behavioural parameter (utilise the same parameter type across ideas within a parameter - e.g. system 2 in cognition). Variation refers to the designers utilising different behavioural parameter types within a parameter (e.g. part, product and system in physical context). Only looking at the number of parameters hold across the 35 concepts, Figure 2 show the distribution of concepts according to number of parameters the designers are holding.

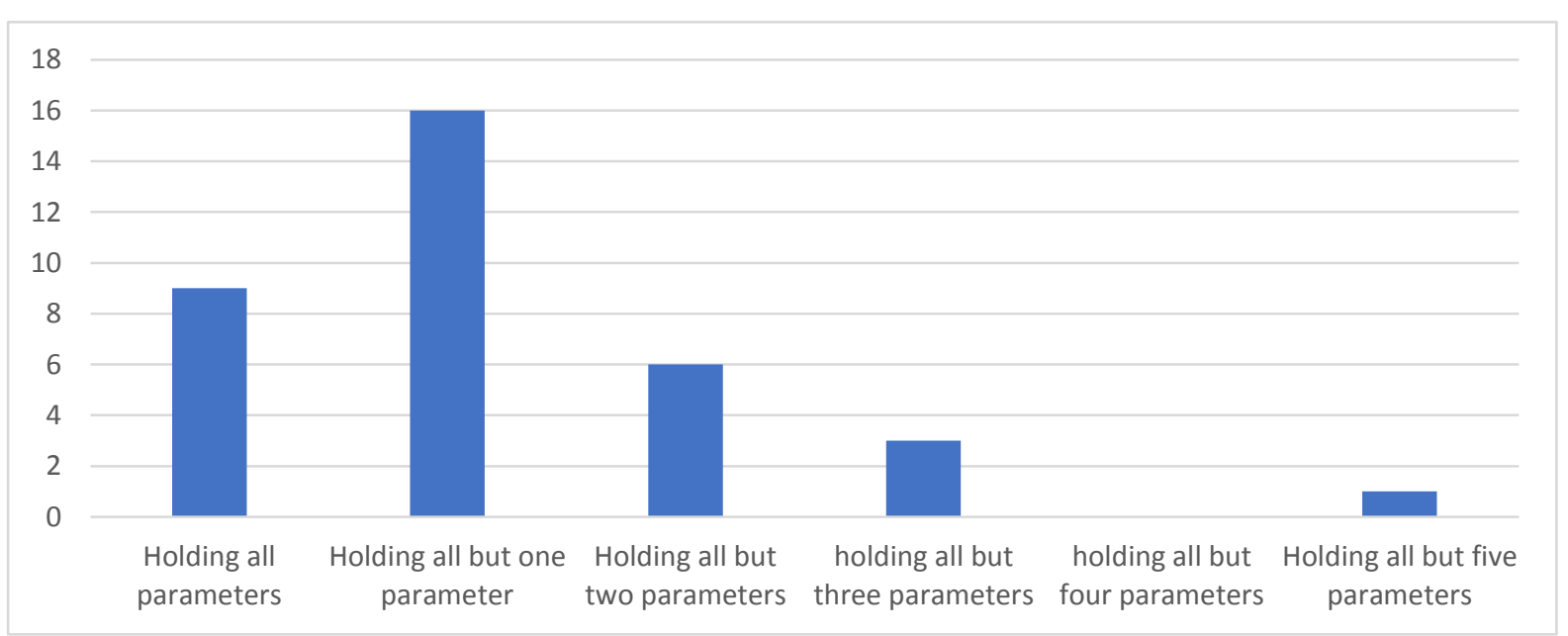

Figure 2. Distribution of concepts according to total number of parameters held

Overall, the findings show that across the two sessions, 25 out of 35 concepts varies a maximum of one parameter. This shows a skewed distribution emphasising a low variation of behavioural design 
parameter types within concepts. Looking in more detail, Table 2 show the distribution of concepts according to which and how many holding behavioural design parameters within the concepts.

Table 2. Overview of concepts emphasising total number of holding parameters as well as specification of varied parameters

\begin{tabular}{|c|c|c|c|c|}
\hline & & & Session 1 & Session 2 \\
\hline Holding all & & In total & $2 / 15$ & $7 / 20$ \\
\hline \multirow{6}{*}{$\begin{array}{l}\text { Holding all, } \\
\text { except one } \\
\text { parameter }\end{array}$} & \multirow{5}{*}{$\begin{array}{l}\text { Parameter } \\
\text { varied }\end{array}$} & Physical context & 5 & 6 \\
\hline & & Timing & 1 & 1 \\
\hline & & Cognition & 1 & \\
\hline & & Motivation & 1 & \\
\hline & & Social context & 1 & \\
\hline & \multicolumn{2}{|r|}{ In total } & $9 / 15$ & $7 / 20$ \\
\hline \multirow{4}{*}{$\begin{array}{l}\text { Holding all, } \\
\text { except two } \\
\text { parameters }\end{array}$} & \multirow{3}{*}{$\begin{array}{l}\text { Parameters } \\
\text { varied }\end{array}$} & Motivation + physical context & 2 & \\
\hline & & Timing + physical context & & 3 \\
\hline & & Social context + physical context & & 1 \\
\hline & \multicolumn{2}{|r|}{ In total } & 2/15 & $4 / 20$ \\
\hline \multirow{4}{*}{$\begin{array}{l}\text { Holding all, } \\
\text { except three } \\
\text { parameters }\end{array}$} & \multirow{3}{*}{$\begin{array}{l}\text { Parameters } \\
\text { varied }\end{array}$} & Timing, ability, physical context & 1 & \\
\hline & & Timing, social context, physical context & & 1 \\
\hline & & Cognition, timing, physica1 context & & 1 \\
\hline & & In total & $1 / 15$ & $2 / 20$ \\
\hline $\begin{array}{l}\text { Holding only } \\
\text { social context }\end{array}$ & & In total & $1 / 15$ & \\
\hline
\end{tabular}

The findings show that 11 out of 16 'holding all, except one' concepts varied physical context, whereas the remaining five concepts varied either cognition, timing, motivation or social context. Also, physical context is varied in all concepts varying two or more parameters, making physical context the parameter varied the most. Looking at fixation and variation on behaviour parameters in more detail, four different ideation patterns was identified: holding, shifting, pairing and mixing.

\subsection{Holding}

The first out of four ideation patterns identified is holding, defined as: all parameter types within a parameter (or all minus one) are the same across the concept. 155 out of 210 concept parameters (35 concepts times six parameters) were identified as holding, making this the most represented pattern.

Table 3. Example: ideation pattern 'holding'

\begin{tabular}{|c|c|c|c|c|c|c|}
\hline $\begin{array}{l}\text { Example: Session 1, concept } 15 \\
\text { Idea element transcriptions }\end{array}$ & Cognition & Ability & Motivation & Timing & $\begin{array}{l}\text { Social } \\
\text { context }\end{array}$ & $\begin{array}{c}\text { Physic } \\
\text { al } \\
\text { context }\end{array}$ \\
\hline $\begin{array}{l}\text { "Replace negative feedback with } \\
\text { positive feedback" }\end{array}$ & \multirow[t]{6}{*}{$\begin{array}{l}\text { Holding } \\
\text { system } 2\end{array}$} & \multirow[t]{6}{*}{$\begin{array}{c}\text { Holding } \\
-\end{array}$} & \multirow[t]{6}{*}{$\begin{array}{l}\text { Holding } \\
\text { Extrinsic }\end{array}$} & \multirow[t]{6}{*}{$\begin{array}{l}\text { Holding } \\
\text { After }\end{array}$} & - & Part \\
\hline "Reward wanted behaviour" & & & & & - & \multirow{5}{*}{$\begin{array}{l}\text { Holdin } \\
\text { g } \\
\text { Syste } \\
\text { m }\end{array}$} \\
\hline $\begin{array}{l}\text { "At every Friday bar expose all } \\
\text { employees that behaved well" }\end{array}$ & & & & & \multirow[t]{4}{*}{$\begin{array}{l}\text { Holding } \\
\text { Community }\end{array}$} & \\
\hline $\begin{array}{l}\text { "Show pictures of all cars that } \\
\text { drove through the tunnel" }\end{array}$ & & & & & & \\
\hline $\begin{array}{l}\text { "Employees parking legally is } \\
\text { blitzed" }\end{array}$ & & & & & & \\
\hline $\begin{array}{l}\text { "The blitzed pictures are showed } \\
\text { on a large screen in lunch room", }\end{array}$ & & & & & & \\
\hline
\end{tabular}


Looking at the behavioural parameters in this example all parameters are identified as holding. In cognition, all six idea elements utilise 'system 2' cognition. None of the idea elements touch upon ability, as such, ability is identified as holding 'non addressed'. All six idea elements utilise 'extrinsic motivation', and 'after' in timing. Social context is also identified as holding, as more than half the idea elements are addressed and all utilise 'community'. Lastly, all idea elements apart from one utilise 'system' in physical context. The transcriptions show that the idea elements build on the same core idea (replacing negative feedback) providing both additional detail (rewarding desired behaviour), as well as proposing alternative ways of exposing people who perform the desired behaviour. As such, looking at the transcriptions only, this concept provides both additional depth as well as some degree of variation. However, in the behavioural parameters the idea progression shows little variation across the behavioural parameters. As such, from a behavioural perspective the solution space is under-explored.

\subsection{Shifting}

Apart from holding, we identify three distinct ideation patterns that vary parameter types. The first of these is shifting, defined as: between every (or every other) idea element the parameter type changes, and often all parameter types will be represented. 15 out of 210 concept parameters were identified as shifting. Shifting is therefore underrepresented compared to holding, however represented to the same degree as the remaining two ideation patterns.

Table 4. Example: ideation pattern 'shifting'

\begin{tabular}{|c|c|c|c|c|c|c|}
\hline $\begin{array}{l}\text { Example: Session 2, concept } \\
19 \\
\text { Idea element transcriptions }\end{array}$ & Cognition & Ability & Motivation & Timing & $\begin{array}{l}\text { Social } \\
\text { context }\end{array}$ & $\begin{array}{l}\text { Physical } \\
\text { context }\end{array}$ \\
\hline $\begin{array}{l}\text { "Message: 'would you like to } \\
\text { be alerted?"," }\end{array}$ & \multirow[t]{5}{*}{$\begin{array}{l}\text { Holding } \\
\text { system } 2\end{array}$} & \multirow[t]{5}{*}{$\begin{array}{l}\text { Holding } \\
\text { mental }\end{array}$} & \multirow[t]{5}{*}{$\begin{array}{l}\text { Holding } \\
\text { extrinsic }\end{array}$} & \multirow[t]{4}{*}{$\begin{array}{l}\text { Holding } \\
\text { before }\end{array}$} & \multirow[t]{5}{*}{$\begin{array}{l}\text { Holding } \\
\text { individual }\end{array}$} & Part \\
\hline $\begin{array}{l}\text { "Message: 'When do you } \\
\text { normally work out?,"” }\end{array}$ & & & & & & Part \\
\hline $\begin{array}{l}\text { "Alerts will be shown on the } \\
\text { phone's home screen" }\end{array}$ & & & & & & $\begin{array}{c}\text { Shifting to } \\
\text { system }\end{array}$ \\
\hline $\begin{array}{l}\text { "Message: 'Remember that } \\
\text { you have to take product"" }\end{array}$ & & & & & & $\begin{array}{c}\text { Shifting to } \\
\text { part }\end{array}$ \\
\hline $\begin{array}{l}\text { "Options for alerts are } \\
\text { 'accept' or 'snooze } 5 \\
\text { minutes }, \text { ", }\end{array}$ & & & & During & & $\begin{array}{l}\text { Shifting to } \\
\text { system }\end{array}$ \\
\hline
\end{tabular}

In this example, the first five parameters are identified as holding, whereas physical context is identified as shifting as the designers vary parameter type back on forth from part to system. Looking at idea element one and two, the designers start with ideas for providing specific information/questions, followed by how additional functions as alerts might show and operate in the system - moving back and forth between the two. Looking at the transcriptions only, we see a concept evolving as each idea element builds on the previous, providing details on concrete information, and structural details to how the information flow might be 'physically structured' on a phone. As such, here the transcripts and behavioural parameters both show fixation and some variation, since the following idea elements provide more detail to previous idea elements, however, from a behavioural perspective, the solution space is again under-explored, with only variation of physical context.

\subsection{Pairing}

The third ideation pattern identified is pairing, defined as: idea elements are held on the same parameter type, varied once and again held on that particular parameter type. 16 out of 210 concept parameters were identified as pairing. 
Table 5. Example: ideation pattern 'pairing'

\begin{tabular}{|c|c|c|c|c|c|c|}
\hline $\begin{array}{l}\text { Example: Session } 1 \text {, concept } 8 \\
\text { Idea element transcriptions }\end{array}$ & Cognition & Ability & Motivation & Timing & $\begin{array}{l}\text { Social } \\
\text { context }\end{array}$ & $\begin{array}{l}\text { Physical } \\
\text { context }\end{array}$ \\
\hline "Create a separate cycle path" & \multirow[b]{2}{*}{ System 1} & \multirow[b]{2}{*}{ Physical } & \multirow[b]{2}{*}{ Intrinsic } & \multirow[b]{2}{*}{ Before } & \multirow{4}{*}{$\begin{array}{l}\text { Holding } \\
\text { individual }\end{array}$} & Product \\
\hline $\begin{array}{l}\text { "Divide the road into a walking } \\
\text { and a biking section" }\end{array}$ & & & & & & $\begin{array}{l}\text { Shifting to } \\
\text { system }\end{array}$ \\
\hline $\begin{array}{l}\text { "Information: 'Cyclists in } \\
\text { here,", }\end{array}$ & \multirow[t]{2}{*}{ System 2} & \multirow[t]{2}{*}{ Mental } & \multirow[t]{2}{*}{ Extrinsic } & \multirow[t]{2}{*}{ During } & & $\begin{array}{c}\text { Shifting to } \\
\text { part }\end{array}$ \\
\hline $\begin{array}{l}\text { "Put the information on a big } \\
\text { sign" }\end{array}$ & & & & & & $\begin{array}{c}\text { Shifting to } \\
\text { product }\end{array}$ \\
\hline
\end{tabular}

In this example, the first four parameters are identified as pairing, whereas social context is identified as holding, and physical context as shifting. Looking at the transcriptions, we see that the first two idea elements focus on the how to create a physical path for cycling, the first proposing the overall idea, and the following idea element specifying that idea further. We see the same structure for the next two idea elements, where the third idea element propose a reinforcement of the first two ideas by adding information, and the last specifies that the information can be manifested in a physical sign. As such, this pairing of the first two and last two idea elements both show when looking at the transcripts, and when looking at the behavioural parameters; where the first two ideas hold system 1, physical ability, intrinsic motivation, and before in timing, and then shifts to system 2 , mental ability, extrinsic motivation, and during in timing, respectively.

\subsection{Mixing}

The last identified ideation pattern is mixing, defined as: the parameter types employ a mix of holding and/or shifting and/or pairing between idea elements within the concept. 12 out of 210 concept parameters were identified as mixing.

Table 6. Example: ideation pattern 'mixing'

\begin{tabular}{|c|c|c|c|c|c|c|}
\hline $\begin{array}{l}\text { Example: Session } 2 \text {, concept } 2 \\
\text { Idea element transcriptions }\end{array}$ & Cognition & Ability & Motivation & Timing & $\begin{array}{c}\text { Social } \\
\text { context }\end{array}$ & $\begin{array}{l}\text { Physical } \\
\text { context }\end{array}$ \\
\hline $\begin{array}{l}\text { "Create a 'how to use these } \\
\text { products' feature in app" }\end{array}$ & \multirow{4}{*}{$\begin{array}{l}\text { Holding } \\
\text { system } 2\end{array}$} & \multirow{7}{*}{$\begin{array}{l}\text { Holding } \\
\text { mental }\end{array}$} & \multirow[t]{2}{*}{ Intrinsic } & \multirow{7}{*}{$\begin{array}{l}\text { Holding } \\
\text { before }\end{array}$} & \multirow{7}{*}{$\begin{array}{l}\text { Holding } \\
\text { individual }\end{array}$} & \multirow{3}{*}{ Part } \\
\hline $\begin{array}{l}\text { "Ask: 'what products do you } \\
\text { use?"" }\end{array}$ & & & & & & \\
\hline $\begin{array}{l}\text { "Ask: 'when do you work } \\
\text { out?"' }\end{array}$ & & & \multirow{5}{*}{$\begin{array}{l}\text { Holding } \\
\text { extrinsic }\end{array}$} & & & \\
\hline $\begin{array}{l}\text { "Use data to add reminders on } \\
\text { taking product in the user's } \\
\text { calendars" }\end{array}$ & & & & & & System \\
\hline $\begin{array}{l}\text { "Put reminders on user's home } \\
\text { screens on the phone" }\end{array}$ & System 1 & & & & & \\
\hline $\begin{array}{l}\text { "Prompt the users to review } \\
\text { the products after use" }\end{array}$ & \multirow{2}{*}{$\begin{array}{l}\text { Holding } \\
\text { system } 2\end{array}$} & & & & & Part \\
\hline $\begin{array}{l}\text { "Prompt the users when the } \\
\text { products you use are on sale } \\
\text { and you are about to be empty" }\end{array}$ & & & & & & System \\
\hline
\end{tabular}

In this example, the first five concept parameters are identified as holding, whereas the physical context is identified as mixing; the first three parameters types refer as 'part', the next two as 'system', then 'part', and lastly as 'system'. As such, in physical context the designers start by pairing 'part' and 'system', and follow by shifting back and forth between 'system' and 'part'. Looking at the idea transcriptions, we see 
that each idea element provide new detail varying from features, to information triggers, to action triggers, and 'infrastructural' details. As such, looking at the transcripts alone, we see a concept evolving; however, when we look at the behaviour parameters the concept mostly evolve on the physical context parameter, pointing again to an under-explored behavioral design solution space. In addition, we only see a mix of the upper and lower level of physical context, and a lack of 'product' level.

\section{Discussion}

Across the two sessions, 25 out of 35 concepts varies a maximum of one parameter showing that holding is by far the most represented ideation pattern. This points to a high fixation throughout the ideation sessions, which is in line with prior fixation research (Kohn and Smith, 2011), as people naturally ideate based on a combination of tacit knowledge and prior experience. In addition, is it commonly seen that people build on previous ideas proposed by others during free ideation. In this study, within concepts, the designers most often vary physical context, which is varied in 21 concepts. Also, we see the focus on physical space in both sessions, even though the topic of the second session (software support for purchase and use of [product]) is not a physical problem by nature. At first glance, this might not be surprising as physical context is arguably the most tangible parameter compared to cognition, ability, motivation, timing and social context, and therefore it is likely more tempting to focus on. Looking at the findings overall, we see that concept parameters are held 155 out of 210 times, and varied (shifted, paired, or mixed) 43 times. The last 12 times is 'non addressed parameter', mainly identified in the ability parameter. This points to ability being 'easiest to ignore' when freely ideating solutions to behavioural problems. However, keeping in mind that the case study is conducted in an expert behavioural design agency, and that the employees present (amongst other backgrounds) have a psychology background, it is surprising to find the high amount of fixation across all behavioural parameters except physical context. These findings point to a low level of exploration of behavioural parameters even by expert behavioural designers, as thereby in line with previous research (Cash et al., 2017; Nielsen et al., 2018) to the need for development and testing of tools and methods specific for exploring behavioural problems and generating concepts for behavioral change. These findings show that such tools and methods should be designed to deal with fixation due to priming of the problem at hand as well as from people present. By doing that, tools and method should help designers to increase exploration of behaviour parameters, and thereby provide a stronger ground for designing effective interventions. In addition to this, the findings motivate future research on defining the behavioural design space, and exploring how activities prior to ideation, for example reframing, and post to ideation, for example prototyping can utilise behavioural parameters.

\section{Limitations}

By nature, the qualitative analysis chosen for this case study comes with limitations. As such, the findings are limited to the two cases studied. Nevertheless, the findings provide a deep initial understanding of how the behavioural design space was explored by expert behavioural designers, as this research study two distinctively different, real life behavioural problems tackled. The findings provide key insight to how this space was explored in the format of free ideation. Second, there is, to the authors knowledge, still no framework for defining the behavioural specific solution space, and therefore also no existing approach to assessing ideation of behavioural problems. However, this paper builds on the initial attempt to investigate the behavioural design solution space (Nielsen et al., 2018), here deriving six key behavioural parameters from existing theory. As such, the paper cannot discuss the quality of the ideated concepts, nevertheless, it is still suitable for discussing ideation patterns identified. Here, the findings point to value of having a framework to assess creative outcomes on behavioural parameters. In addition, they are in line with previous research pointing to the need of developing behaviour specific methods and tool, as the finding show that behavioural problems are of a complexity difficult even for expert behavioural designers.

\section{Conclusion}

This study examined the creative outcome of two real world ideation sessions in an expert behavioural agency. Idea elements were identified from video recordings, assessed on six proposed behavioural 
parameters (cognition, ability, motivation, timing, social and physical context), and grouped into concepts. In total, 35 concepts were identified and further investigated, revealing four distinct ideation patterns: holding, shifting, pairing, and mixing. Holding is fixation of behavioural parameters, whereas shifting, pairing, and mixing are different ways of varying behavioural parameters. The findings showed, that the designers favoured holding as only 10 out of 35 concepts varied more than two behavioural parameters in a concept. This point to an overall high fixation across all behavioural parameters apart from physical context, which was varied in 21 concepts. Overall, this study show that when working with complex behavioural problems exploring the behavioural design space is difficult even for expert behavioural designers. Therefore, the results point to a need for development and application of behavioural design support to increase both understanding and exploration of the solution space from a behavioural perspective.

\section{Acknowledgments}

The authors would like to thank DTU for funding the research, the agency for inviting us to their ideation sessions, Johan Aakerlund for contributing to data collection, and Kittima Ratana-Rueangri for contributing to data analysis.

\section{References}

Andreasen, M.M., Hansen, C.T. and Cash, P. (2015), Conceptual Design: Interpretations, Mindset and Models, Springer. https://doi.org/10.1007/978-3-319-19839-2

Akrich, M. (1992), “The De-Scription of Technical Objects”, In: Bijker, W.E. and Laws, J. (Eds.), Shaping Technology/Building Society: Studies in Sociotechnical Change, MIT Press, Cambridge, MA.

Bronfenbrenner, U. (1986), "Ecology of the family as a context for human development: Research perspectives", Developmental psychology, Vol. 22 No. 6, p. 723. https://doi.org/10.1037/0012-1649.22.6.723

Bronfenbrenner, U. (1989, April), "The developing ecology of human development: Paradigm lost or paradigm regained", Biennial meeting of the Society for Research in Child Development, Kansas City, MO.

Cash, P.J., Hartlev, C.G. and Durazo, C.B. (2017), "Behavioural design: A process for integrating behaviour change and design", Design Studies, Vol. 48, pp. 96-128. https://doi.org/10.1016/j.destud.2016.10.001

Cash, P. and Štorga, M. (2015), "Multifaceted assessment of ideation: using networks to link ideation and design activity", Journal of Engineering Design, Vol. 26 No. 10-12, pp. 391-415. https://doi.org/10.1080/ 09544828.2015.1070813

Chaiken, S. and Trope, Y. (Eds.). (1999), Dual-process theories in social psychology, Guilford Press.

Cialdini, R.B. and Goldstein, N.J. (2004), "Social Influence: Compliance and Conformity", Annual Review of Psychology, Vol. 55 No. 1, pp. 591-621. https://doi.org/10.1146/annurev.psych.55.090902.142015

Cialdini, R.B. (2007), Influence: The psychology of persuasion, Collins, New York.

Crilly, N. and Cardoso, C. (2017), "Where next for research on fixation, inspiration and creativity in design?", Design Studies, Vol. 50, pp. 1-38. https://doi.org/10.1016/j.destud.2017.02.001

Eisenhardt, K.M. and Graebner, M.E. (2007), "Theory building from cases: Opportunities and challenges", Academy of Management Journal, Vol. 50 No. 1, pp. 25-32. https://doi.org/10.5465/amj.2007.24160888

Fogg, B.J. (2009a, April). Creating persuasive technologies: an eight-step design process. Proceedings of the 4th international conference on persuasive technology, 44. ACM. https://doi.org/10.1145/1541948.1542005

Fogg, B.J. (2009b, April). A behavior model for persuasive design. Proceedings of the 4th international Conference on Persuasive Technology, 40. ACM. https://doi.org/10.1145/1541948.1541999

Fogg, B.J. (2019), Tiny habits: the small changes that changes everything, Houghton Mifflin Harcourt Publishing Company.

Goldschmidt, G. (2014), Linkography: Unfolding the design process, The MIT press, Cambridge, Massachusetts. https://doi.org/10.7551/mitpress/9455.001.0001

Guilford, J.P. (1956), “The structure of intellect”, Psychological Bulletin, Vol. 53 No. 4, p. 267. https://doi.org/ $10.1037 / \mathrm{h} 0040755$

Jansson, D.G. and Smith, S.M. (1991), "Design fixation”, Design Studies, Vol. 12 No. 1, pp. 3-11. https://doi.org/10.1016/0142-694x(91)90003-f

Jauk, E., Benedek, M. and Neubauer, A.C. (2012), "Tackling creativity at its roots: Evidence for different patterns of EEG alpha activity related to convergent and divergent modes of task processing", International Journal of Psychophysiology, Vol. 84 No. 2, pp. 219-225. https://doi.org/10.1016/j.ijpsycho.2012.02.012

Kahneman, D. (2011), Thinking, fast and slow, Macmillan.

Karbach, J. and Schubert, T. (2013), "Training-induced cognitive and neural plasticity", Front Hum Neurosci, Vol. 7, p. 48. https://doi.org/ 10.3389/fnhum.2013.00048 
Kohn, N.W. and Smith, S.M. (2011), "Collaborative fixation: Effects of others' ideas on brainstorming", Applied Cognitive Psychology, Vol. 25 No. 3, pp. 359-371. https://doi.org/10.1002/acp.1699

Latour, B. (1992), "Where Are the Missing Masses? The Sociology of a Few Mundane Artifacts", In: Bijker, W.E. and Laws, J. (Eds.), Shaping Technology/Building Society: Studies in Sociotechnical Change, MIT Press, Cambridge, MA.

Michie, S., Van Stralen, M.M. and West, R. (2011), "The behaviour change wheel: a new method for characterising and designing behaviour change interventions", Implementation Science, Vol. 6 No. 1, p. 42. https://doi.org/10.1186/1748-5908-6-42

Miltenberger, R.G. (2011), Behavior modification: Principles and procedures, Cengage Learning.

Mumford, M.D., Connelly, S. and Gaddis, B. (2003), "How creative leaders think: Experimental findings and cases", The Leadership Quarterly, Vol. 14 No. 4-5, pp. 411-432. https://doi.org/10.1016/s10489843(03)00045-6

Nielsen, C.K.E.B.B., Cash, P. and Daalhuizen, J. (2018), “The behavioural design solution space: examining the distribution of ideas generated by expert behavioural designers", DS92: Proceedings of the DESIGN 2018 15th International Design Conference, Design Society, pp. 1981-1990. https://doi.org/10.21278/ idc. 2018.0212

Niedderer, K., Clune, S. and Ludden, G. (Eds.). (2017). Design for Behaviour Change: Theories and practices.

Prochaska, J.O. (1979), Systems of psychotherapy: A transtheoretical analysis, Dorsey Press, Homewood, IL. https://doi.org/10.4324/9781315576602

Rantanen, K., Conley, D.W. and Domb, E.R. (2017), Simplified TRIZ: New Problem Solving Applications for Technical and Business Professionals, Productivity Press. https://doi.org/10.1201/b22111-13

Ryan, R.M. and Deci, E.L. (2000), When Rewards Compete with Nature: The Undermining. Intrinsic and extrinsic motivation: The search for optimal motivation and performance, 13. https://doi.org/10.1016/b978012619070-0/50024-6

Schell, J. (2014), The Art of Game Design: A book of lenses, AK Peters/CRC Press. https://doi.org/10.1201/b17723

Sunstein, C. and Thaler, R. (2008), Nudge. The politics of libertarian paternalism, New Haven. https://doi.org/ $10.2139 /$ ssrn.405940

Tromp, N., Hekkert, P. and Verbeek, P.P. (2011), "Design for socially responsible behavior: a classification of influence based on intended user experience", Design Issues, Vol. 27 No. 3, pp. 3-19. https://doi.org/ 10.1162/desi_a_00087

Ward, T.B., Smith, S.M. and Finke, R.A. (1999), “Creative cognition”, In: Sternberg, R.J. (Ed.), Handbook of Creativity, Cambridge University Press, New York, NY, pp. 189-212. https://doi.org/10.1017/cbo9780511807916.012

Wendel, S. (2013), Designing for behavior change: Applying psychology and behavioral economics, O'Reilly Media, Inc.

Yin, R.K. (2013), Case study research: Design and methods, Sage publications. 